\title{
Effect of Color in Human Life
}

\author{
Sunny Sharma \\ Shubharti university \\ Meerut
}

\section{"Most people are unaware of he propend effect color has on their behavior"}

Take a minute and imagine the world around you without colors, how boring and unexciting life would be colors play a vital role in our daily lives and if has been proven that our actives and response and influenced by them.

Every color has a unique effect on individuals and stimulates various responses e.g. a research has proven that blue color enhances creativity whereas the colors red helps to be focused and has appositive effect on memory. Dark green color has a motivational effect on males. The color is yellow helps to release a chemicals in the brain called serotonin essentials for causing a happy mood and change are the happiest color. So every color different effect in our life each color corresponds with a vibrations with an every with an element and with a desired out come .getting the colors wrong can at best Make a spell fair and at work could backfires on the spell caster or recipient of the spell manifestation

Colors is the by product of the spectrum of light, as it is reflected or absorbed as received by the human eye as received by the human eye and processed by the human brain color is the visual peaceful property corresponding in humans to the categories called red, yellow, blue, black, green, white, purple, orange e.t.c.

Color derives from the spectrum of light interacting in the eye with the spectrum sensitivities of the light receptors.

Clearly, using color to effect mood and behavior is not an exact since the variables are too many, and the different in response from one individual to the next are too great. Still, research suggest that some colors may tend to have measurable physiological effect on money people, if not all.

Culturally -learned meanings of color are also quite powerful, and can be used to subtly effect mood and behavior in some people. The following list discusses some of the meaning commonly associated with various color in the US and other western societies, as well as the result of scientific study on specific color where applicable.

Sys sir Martine Broman in his work on the body/mirror systems

"Each of the chakras is energy vibrating at a certain frequency. In a logical and orderly sequence of seven vibration. As we move up the scale, elements become more and more subtle, moving through the five element of earth, water, air, fire, and ether, to the spiritual elements of inner sound 
and inner light, the heaviest element is on the bottom, the lightest on the top. It is a logical and orderly sequence.

The color of the spectrum also represent a series of seven vibrations in a logical and orderly sequence, as do the notes of the musical scale. Thus we can put the heaviest vibrations of the longest wavelength on the bottom and the lightest on the top, and a particular color can be used to represent a chakra in its clear state, as can a particular musical note. Music played in a certain key vibrates a particular chakra, and we feel a particular way when we hear that music. Our relationship with a certain color says something about our relationship with the part of our consciousness that the color represents"

Color is one of the most fulfilling elements in our lives. Color can attract your attention or change your mood. It speaks to who you are how you feel and where you're going. Black is the color of authority and power it is popular is fashion because it makes people appear the thinner. It is also stylish and timeless black also implies submission priests wear black to signify submission to god. Some fashion experts say a woman wearing black implies submission to men. Brides wear white to symbolize innocence and punity white effect light and is considered a summer color white is poplar is decoration and in fashion because it is light neutral and goes with everything. the red most emotionally intense color red stimulates a faster heartbeat and breath way it is also the color of love red clothing gets noticed and makes the wears appear heavier, since it in extreme color, red clothing might not help people in negotiations or confrontations, red cars are popular targets for thievery. It decorating red is usually used as an accent decorators say that red furniture should be perfect since it will attract attention the most romantic color pink is more tranquilizing. The color of the sky and the ocean. Blue is one of the most popular colors. It cases the opposite reaction as red peaceful tranquil blue causes the body to produce calming chemicals blue can also be add and depressing currently the most popular decorating color, green symbolres nature it is the easiest color on the eye and can improve vision it is a calming refreshing color people. Cheerful Sunny yellow is also attention getter it is the most difficult color is the most difficult color for the eye to take is so it can be overpowering if overused it also speeds metabolism. The color of royalty, purple connotes luxury, wealth and sophistication it is also feminize and romantic. However because it is rare in nature purple can appear artificial. Yellow is Hinduism Buddhism, energy balance, heat, fire, enthusiasm, play fullness, aggression, arrogance, gudinerres, over emotion warning danger, autumn, desire, calm, depth natural organisms nature, richness reteams stability, tradition, simplistic friendliness and dependability.

"Colors like features, follow the changes of the emotions. Pablo Picasso" 